\title{
Corrigendum: Economic Value of Lost Productivity Attributable to Human Papillomavirus Cancer Mortality in the United States
}

\author{
Masoom Priyadarshini ${ }^{1}$, Vimalanand S. Prabhu ${ }^{2 \star}$, Sonya J. Snedecor ${ }^{1}$, Shelby Corman ${ }^{1}$, \\ Barbara J. Kuter ${ }^{2}$, Chizoba Nwankwo ${ }^{2}$, Diana Chirovsky ${ }^{2}$ and Evan Myers ${ }^{3}$ \\ ${ }^{1}$ Pharmerit - an OPEN Health Company, Bethesda, MD, United States, ${ }^{2}$ Merck \& Co. Inc., Kenilworth, NJ, United States, \\ ${ }^{3}$ Division of Women's Community and Population Health, Department of Obstetrics \& Gynecology, Duke University School of \\ Medicine, Durham, NC, United States
}

Keywords: human papillomavirus, productivity loss, mortality, cervical cancer, oropharyngeal cancer

\section{A Corrigendum on:}

\section{OPEN ACCESS}

Edited and reviewed by: Olatunde Aremu,

Birmingham City University, United Kingdom

*Correspondence:

Vimalanand S. Prabhu vimalanand.prabhu@merck.com

Specialty section:

This article was submitted to

Health Economics,

a section of the journal

Frontiers in Public Health

Received: 06 April 2021 Accepted: 25 June 2021

Published: 26 July 2021

Citation:

Priyadarshini M, Prabhu VS, Snedecor SJ, Corman S, Kuter BJ,

Nwankwo C, Chirovsky D and

Myers E (2021) Corrigendum: Economic Value of Lost Productivity Attributable to Human Papillomavirus Cancer Mortality in the United States.

Front. Public Health 9:691634.

doi: 10.3389/fpubh.2021.691634
Economic Value of Lost Productivity Attributable to Human Papillomavirus Cancer Mortality in the United States

by Priyadarshini, M., Prabhu, V. S., Snedecor, S. J., Corman, S., Kuter, B. J., Nwankwo, C., et al. (2021). Front. Public Health 8:624092. doi: 10.3389/fpubh.2020.624092

In the original article, there was a calculation error underestimating the number of cancer deaths attributable to 9vHPV-targeted types.

In Table 3, the numeric values in the two rows with the subheading High-risk HPV types targeted by 9vHPV have been updated. The corrected Table 3 appears below.

In Table 4, the numeric values in the two rows with the subheadings HPV 16/18 and HPV 31/33/45/52/58 have been updated. The corrected Table 4 appears below.

A correction has been made to some numeric values within the abstract, results, and discussion:

Abstract Results: “An estimated 7,085 HPV-attributable cancer deaths occurred in 2017 accounting for 154,954 YPLL, with 6,482 deaths (91\%) and 141,019 YPLL (91\%) attributable to 9vHPV-targeted types. The estimated PVFLP was $\$ 3.8$ billion for cancer deaths attributable to 9vHPV-targeted types (84\% from women). The highest productivity burden was associated with cervical cancer in women and anal and oropharyngeal cancers in men."

Results sentence 1: "This analysis estimated that a total of 7,085 HPV-attributable cancer deaths occurred in the United States in 2017; of these, 6,482 (91\%) deaths were attributable to the high-risk types targeted by 9vHPV (i.e., HPV 16, 18, 31, 33, 45, 52, and 58; Table 3).”

Results paragraph 3: "The estimated PVFLP for cancer deaths due to HPV 16/18 and HPV 31/33/45/52/58 were $\$ 3.2$ billion (76\%) and $\$ 626$ million (15\%), respectively. The average PVFLP per death among men and women were $\$ 529,248$ and $\$ 608,906$, respectively."

Discussion paragraph 8: "Cancer deaths caused by high-risk 9vHPV-targeted types accounted for $\mathbf{9 1 \%}$ of the total YPLL and total PVFLP.” 
TABLE 3 | Estimated number of HPV-attributable cancer deaths in the United States in 2017 and estimated YPLL associated with HPV-attributable cancer stratified by sex and HPV type.

\begin{tabular}{|c|c|c|c|c|c|c|c|c|c|}
\hline & Total & \multicolumn{5}{|c|}{ Women } & \multicolumn{3}{|c|}{ Men } \\
\hline \multicolumn{10}{|l|}{ Estimated deaths ${ }^{a}$} \\
\hline Any HPV & 7,085 & 3,812 & 308 & 868 & 677 & 182 & 223 & 388 & 628 \\
\hline High-risk HPV types targeted by 9vHPV & 6,482 & 3,403 & 302 & 793 & 661 & 173 & 200 & 362 & 588 \\
\hline \multicolumn{10}{|l|}{ Estimated YPLL } \\
\hline Estimated YPLL per death & 22 & 26 & 14 & 14 & 19 & 18 & 15 & 19 & 17 \\
\hline
\end{tabular}

9vHPV, nonavalent HPV vaccine; HPV, human papillomavirus; YPLL, years of potential life lost.

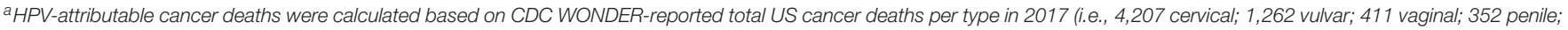
1,169 anal; 1,154 oropharyngeal).

${ }^{b}$ HPV 16, 18, 31, 33, 45, 52, and 58.

TABLE 4 | Estimated present value of future lifetime productivity due to HPV-attributable cancer deaths by sex and HPV type (in thousands, 2017 \$).

\begin{tabular}{|c|c|c|c|c|c|c|c|c|c|}
\hline & \multicolumn{9}{|c|}{ PVFLP By Sex and Cancer Site (\% of Total PVFLP) } \\
\hline & \multirow[t]{2}{*}{ Total } & \multicolumn{5}{|c|}{ Women } & \multicolumn{3}{|c|}{ Men } \\
\hline & & Cervix & Vagina & Vulva & Anus & Oropharynx & Penis & Anus & Oropharynx \\
\hline Any HPV & $\begin{array}{c}4,215,447 \\
(100)\end{array}$ & $\begin{array}{c}2,847,795 \\
(67.6)\end{array}$ & $90,885(2.2)$ & $\begin{array}{c}256,211 \\
(6.1)\end{array}$ & $\begin{array}{c}291,883 \\
(6.9)\end{array}$ & $73,389(1.7)$ & $\begin{array}{c}100,938 \\
(2.4)\end{array}$ & $\begin{array}{c}232,742 \\
(5.5)\end{array}$ & $\begin{array}{c}321,605 \\
(7.6)\end{array}$ \\
\hline HPV 16/18 & $\begin{array}{c}3,203,913 \\
(76.0)\end{array}$ & $\begin{array}{c}2,080,839 \\
(49.4)\end{array}$ & $66,770(1.6)$ & $\begin{array}{c}180,986 \\
(4.3)\end{array}$ & $\begin{array}{c}250,861 \\
(6.0)\end{array}$ & $58,896(1.4)$ & $76,381(1.8)$ & $\begin{array}{c}207,553 \\
(4.9)\end{array}$ & $\begin{array}{c}281,626 \\
(6.7)\end{array}$ \\
\hline HPV 31/33/45/52/58 & $\begin{array}{c}626,077 \\
(14.9)\end{array}$ & $\begin{array}{c}462,059 \\
(11.0)\end{array}$ & 22,176 (0.5) & $52,881(1.3)$ & $34,079(0.8)$ & $11,014(0.3)$ & $14,351(0.3)$ & $9,971(0.2)$ & $19,545(0.5)$ \\
\hline PVFLP per death & 595 & 747 & 295 & 295 & 431 & 404 & 453 & 600 & 512 \\
\hline
\end{tabular}

HPV, human papillomavirus; PVFLP, present value of future lifetime productivity.

In the original article, there was a mistake in the discussion that has been corrected:

Discussion paragraph 10: "However, the statement also acknowledged the non-labor-market value of women who are raising children, caring for their families, and contributing to the social and economic fabric of their communities, a burden that is captured in our analysis but also needs to be evaluated in future studies."

The authors apologize for the errors and state that this does not change the scientific conclusions of the article in any way. The original article has been updated.
Publisher's Note: All claims expressed in this article are solely those of the authors and do not necessarily represent those of their affiliated organizations, or those of the publisher, the editors and the reviewers. Any product that may be evaluated in this article, or claim that may be made by its manufacturer, is not guaranteed or endorsed by the publisher.

Copyright (® 2021 Priyadarshini, Prabhu, Snedecor, Corman, Kuter, Nwankwo, Chirovsky and Myers. This is an open-access article distributed under the terms of the Creative Commons Attribution License (CC BY). The use, distribution or reproduction in other forums is permitted, provided the original author(s) and the copyright owner(s) are credited and that the original publication in this journal is cited, in accordance with accepted academic practice. No use, distribution or reproduction is permitted which does not comply with these terms. 